Geopolítica(s) Revista de estudios sobre espacio y poder ISSN: 2172-3958

https://dx.doi.org/10.5209/geop.69017

\title{
Centroamérica: neoliberalismo y COVID-19
}

\author{
David Díaz Arias $^{1}$ y Ronny Viales Hurtado ${ }^{2}$
}

Recibido: 29 de abril de 2020 / Aceptado: 10 de mayo de 2020

Resumen. Este artículo examina la historia reciente de transformaciones políticas y económicas en Centroamérica y la forma en que esas circunstancias determinan la acción frente a la pandemia global por la COVID-19. Nuestro argumento es que en los últimos años, la región centroamericana ha vuelto a tener gobiernos conservadores y de derecha que han consolidado una reforma neoliberal cuyos resultados han sido el crecimiento de la desigualdad y la pobreza en la región. En ese marco, el impacto de la pandemia no solo será en la salud pública, sino en la economía y en la ampliación de la pobreza en Centroamérica. Por eso, las elites deben cambiar su actitud egoísta y autoritaria para poder sortear esa tremenda crisis.

Palabras clave: pandemia de COVID-19; Centroamérica; neoliberalismo; desigualdad; elites.

\section{[en] Central America: Neoliberalism and COVID-19}

\begin{abstract}
This essay examines the current political and economic changes in Central America and how these policies determine the way this region can react to the coronavirus pandemic. We point out that conservative and right-wing governments have re-emerged in Central America over the last few years and are committed to consolidating neoliberal reforms in these countries. Poverty and inequality produced by neoliberal reforms set the scenario in which the region confronts the pandemic. We argue that the consequences of the pandemic and the neoliberal reforms will be dramatic if Central American elites do not change their selfish and authoritarian attitude towards the poor.
\end{abstract}

Keywords: COVID-19 pandemic; Central America; neoliberalism; inequality; elites.

\section{[pt] América Central: neoliberalismo e COVID-19}

Resumo. Este artigo examina a história recente de transformações políticas e econômicas na América Central e a maneira como essas circunstâncias determinam a ação contra a pandemia global por COVID-19. Nosso argumento é que, nos últimos anos, a região da América Central voltou a ter governos conservadores e de direita que consolidaram uma reforma neoliberal cujos resultados foram o crescimento da desigualdade e da pobreza na região. Nesse contexto, o impacto da pandemia não será apenas na saúde pública, mas na economia e na expansão da pobreza na América Central. Por esse

1 Catedrático de Historia, Universidad de Costa Rica.

E-mail: david.diaz@ucr.ac.cr

2 Catedrático de Historia, Universidad de Costa Rica.

E-mail: ronny.viales@ucr.ac.cr 
motivo, as elites devem mudar sua atitude egoísta e autoritária para poderem superar essa tremenda crise.

Palavras-chave: pandemia da COVID-19; América Central; neoliberalismo; desigualdade; elites.

Sumario. 1. Una región pobre. 2. Neoliberalismo tropical. 3. Protestas y COVID-19. ¿Qué hacer? Referencias.

Cómo citar: Díaz Arias, D., y Viales Hurtado, R. (2020). Centroamérica: neoliberalismo y COVID19. Geopolítica(s). Revista de estudios sobre espacio y poder, 11(Especial), 39-45.

\section{Una región pobre}

Hacia finales de noviembre de 2019, cuando se comenzaba a alertar sobre el desarrollo de una nueva enfermedad en la ciudad de Wuhan (China), América Latina estaba alzada contra sus gobiernos. En aquellos días y unos meses antes, había grandes manifestaciones sociales en Chile, Ecuador, Argentina, Puerto Rico y Bolivia, mientras que otros movimientos se alargaban desde el año 2018, como el de revueltas en Nicaragua contra el gobierno de Daniel Ortega y Rosario Murillo. Esos movimientos sociales, sin ninguna duda, eran liderados por jóvenes, pero también tenían un profundo contenido de clase y levantaban las banderas de reivindicaciones de género, pero también étnicas. Vistos en la larga duración, eran verdaderos levantamientos que exponían con fuerza un desagrado con la política y los políticos latinoamericanos, pero también con las reformas estructurales que habían sucedido en sus países desde el giro a la derecha que ocurrió a principios del siglo XXI (Quinteros y Moreira, 2018).

En el año 2009, en la "olvidada" Centroamérica, un acontecimiento mostró las cadenas del pasado antes de que se renovaran en otras partes; en ese año, el presidente hondureño Manuel Zelaya sufrió un golpe de Estado, por la noche - como solían ser en el siglo pasado-, fue puesto en un avión y sacado del país. Ese golpe convirtió a Honduras en un infierno para los líderes sociales, los grupos opositores y también para los ambientalistas, hasta el día de hoy. Además, puso en la palestra la posibilidad de que, otra vez, los golpes de Estado jugaran un papel en la política latinoamericana. Así, no fue la elección de Sebastián Piñera en Chile, en 2010, la que cambiaba el camino de izquierda a derecha en el continente, pero sí, claramente, esa elección fue la que lo comenzaba a consolidar. En los siguientes años, América Latina vivió varios momentos similares a lo vivido en Centroamérica: en junio de 2012, el presidente paraguayo Fernando Lugo sufrió un golpe de Estado producido desde el Congreso. En el año 2016, Dilma Rousseff sufrió un impeachment, que básicamente repitió la misma técnica de desconocer el poder de las urnas desde el Congreso, que significó, entre otras cosas, la globalización del lawfare, una estrategia de "guerra legal", como lo ha señalado Orde Kittrie (2015), que impone más límites a la democracia delegativa (O’Donnell, 1994) neoliberal. En el caso nicaragüense, la cuestión política era, irónicamente, un retorno al pasado. ¿Cómo podría Centroamérica enfrentar, y con qué infraestructura, la llegada de nuevos gobiernos autoritarios y de la pandemia de COVID-19?

El Primer Informe del Estado de la Región de Centroamérica fue presentado en 1999. En este, al evaluar la década de 1990 como una "década positiva", se afirma- 
ba y celebraba que ninguno de los regímenes autoritarios existentes en 1978 sobrevivía en la región para ese año. Asimismo, indicaba que la región entera estaba motivada por la esperanza en el desarrollo de la democracia y la sujeción del poder militar al civil. El Segundo Informe (2003) ya no pintó un paisaje tan halagüeño. Más bien, manifestó dudas sobre el avance democrático y social de la región y planteó, por primera vez, una idea que comenzará a repetirse en los siguientes informes: que había un "rezago histórico" en la región en términos de democratización. El Tercer Informe (2008) señaló nuevas dudas, ahora ampliadas a cómo Centroamérica enfrentaría los desafíos globales. Esos retos se resumían como la "corrosiva geopolítica de seguridad vinculada al narcotráfico, la creciente vulnerabilidad de la inserción económica internacional de los países más rezagados del área y los altos precios internacionales de los hidrocarburos y los alimentos". El Cuarto Informe (2011) enfrentó los vaticinios del 2008 y afirmó que, afortunadamente, los peores pronósticos no se cumplieron. Aún así, el desarrollo diferenciado de la región era muy claro en los datos que se aportaban y se marcaba en las desigualdades entre el desarrollo del norte y el del sur de Centroamérica. Asimismo, aparece en este informe una de las etiquetas que mejor refleja una de las mayores problemáticas de Centroamérica: se trataba del territorio más violento de América Latina.

En el 2016 se presentó el Quinto Informe. Para ese momento, la población centroamericana era de casi 46 millones de habitantes; $41,4 \%$ de esa población era rural y $58,6 \%$ era urbana. Este informe confirma algunos de los peores escenarios dibujados desde los buenos augurios de 1999. Así, el avance en términos políticos parecía detenido y la democracia no se ha fortificado. El informe indica que algunos partidos políticos gozaban de una consolidación lograda después de 1990, pero muchos funcionan básicamente en términos electorales.

Pero no todo era malo. El istmo centroamericano había avanzado en la reducción de las tasas de mortalidad infantil, el aumento de la asistencia escolar y la elevación de la esperanza de vida. El gran desafío, empero, lo seguía representando la desigualdad. En el año 2013, un $47 \%$ de la población centroamericana se encontraba bajo la línea de pobreza y el $18 \%$ de esa población vivía en la indigencia. Entre 2009 y 2014 la proporción de hogares en exclusión social pasó de 36 a 42\%. 4,2 millones de hogares en el istmo estaban fuera del mercado laboral y sin acceso a los servicios sociales básicos. ¿Cómo se enfrenta una pandemia global con esas condiciones de desigualdad y pobreza?

\section{Neoliberalismo tropical}

Las problemáticas sociales y económicas en Centroamérica coinciden con el ascenso del neoliberalismo, incluso a pesar de que a fines del siglo XX se aseguraba que ese era un proyecto que estaba herido de gravedad (French, 2009; Murillo, 2000). Pero aquí, nuevamente, se deben realizar precisiones sobre de qué hablamos cuando hablamos de neoliberalismo. Para eso, tenemos que apartarnos del neoliberalismo como fenómeno solamente vinculado a transformaciones económicoinstitucionales, como se definió a inicios de la década de 1980 y se consolidó en la década de 1990, y pensarlo siguiendo las ideas de Wendy Brown (2009) y, más abiertamente, de Christian Laval y Pierre Dardot (2016): 
1. Este neoliberalismo no es un fenómeno solamente dentro del Estado, como si fuera básicamente un conjunto de reformas institucionales; es una reacción del capitalismo a ultranza contra el Estado.

2. En esa misma línea, el neoliberalismo no consiste en un ataque de las corporaciones multinacionales al gobierno, sino que los gobiernos participan de ese ataque como cómplices.

3. En términos políticos, el neoliberalismo se constituye como una nueva racionalidad de gobernanza en la cual el Estado es entendido por los empresarios como una empresa más.

4. Dentro de esa nueva racionalidad, somos controlados por lo que escogemos: el neoliberalismo disemina valores del mercado en todos los sentidos culturales.

5. Esta nueva racionalidad busca la producción de un sujeto neoliberal: somos empresarios de nosotros mismos y nos presionamos para rendir más y obtener más ganancias personales.

6. Este neoliberalismo ve el mercado como construcción no como producto natural tal y como se postulaba en el pasado. Y, en vista de que el mercado es un constructo, los neoliberales se comprometen a construirlo con el Estado.

7. El neoliberalismo es peligroso para la democracia liberal porque la aniquila. Justamente, es en esta dimensión donde más revela su condición conservadora.

A la par de esos procesos de deslegitimación, América Latina entró en una desaceleración económica que hizo que el Fondo Monetario Internacional asegurara, en el año 2012, que la región había perdido 10 años de desarrollo económico (FMI, 2012, pp.85-89). Ese fue el contexto en que también los gobiernos de izquierda en Centroamérica fueron acusados de corrupción en El Salvador y en Nicaragua. Guatemala ha sido un caso particularmente interesante, porque, a pesar de que no tuvo un giro real a la izquierda, las acusaciones de una corrupción política tan descarada abrieron un espacio de posibilidades de transformación que, sin embargo, no llevó al electorado a que se decantara por la izquierda, como quizás hubiera ocurrido a inicios del siglo, sino que se lanzó hacia la derecha al elegir un gobierno conservador dirigido por un comediante.

La pobreza generada por el neoliberalismo no es solo centroamericana. A mediados del 2019, el número de pobres en América Latina rondaba los 190 millones, de los cuales unos 70 millones, es decir un 36 por ciento de esa población en pobreza, se encontraban en pobreza extrema (CEPAL, 2019, pp.95-124). Así que, las reformas que se habían desarrollado en el continente desde finales del siglo $\mathrm{XX}$, cuyo sentido llevaba a transformar las actividades de los Estados y a abrir los mercados, no habían tenido ningún éxito en rescatar a la gran mayoría de pobres, pero, además, habían impactado a las clases medias de forma que casi las había eliminado. La concentración de poder y dinero en unos cientos de ultra-millonarios latinoamericanos era el indicador más convincente de que los gobiernos no habían dirigido sus fuerzas a lograr mayor igualdad en sus poblaciones y que América Latina estaba ingresando en una época de "rebelión de las elites", como ha planteado Christopher Lasch (1995) para el caso de los Estados Unidos. 


\section{Protestas y COVID-19}

La llegada de la COVID-19 a América Central ocurrió en marzo de 2020. La nueva enfermedad estaba mostrando en Europa que los sistemas de sanidad pública no resistían si no se tomaban medidas urgentes de "distanciamiento social" y control de las reuniones grupales. Ese distanciamiento creó la oportunidad para que se abrieran espacios para un nuevo pacto social basado en la solidaridad, pero, en la práctica, el distanciamiento físico también ha resultado ser social, porque se trata de una enfermedad que se vuelve más letal en la medida en que se tienen factores de riesgo que se vinculan con la edad y el padecimiento de patologías asociadas, pero también con carencias socioeconómicas.

Uno de los grandes problemas, empero, es que los sistemas de salud en Centroamérica, con la excepción de Costa Rica, están poco preparados para enfrentar la pandemia. En esta región, las protestas también bajaron de intensidad o desaparecieron en la medida en que, a partir de mediados de marzo de 2020, se alertaba sobre la presencia del virus. En este sentido, las sociedades centroamericanas, empobrecidas y con élites egoístas y en algunos casos corruptas, tienen mayores problemas económicos y sociales, que van más allá de solo imaginar los efectos de la pandemia. En El Salvador, el presidente Nayib Bukele, que traía ya un comportamiento autoritario desde que asumió el mando, en junio de 2019, cerró su país muy rápido para evitar el contagio, pero ha llevado adelante violaciones a los Derechos Humanos, como encerrar en verdaderas prisiones a decenas de viajantes que retornaban al país y que fueron hacinados con falta de agua y de higiene, en pequeñas pocilgas o utilizar la coyuntura para reprimir con más fuerza a las maras. Su comportamiento, que involucra gobernar con tweets, se acerca mucho y muy peligrosamente, al talante dictatorial que en otras épocas han tenido los mandatarios en El Salvador. Las pandillas organizadas salvadoreñas, por su parte, implementaron sus propias medidas y toque de queda en las regiones que dominan y contuvieron la violencia por unas semanas, pero volvieron a ella a finales de abril del 2020 , de forma que la situación se tornó más compleja. En Guatemala, el presidente Alejandro Giammattei actuó de forma parecida, al dejar a 182 migrantes deportados desde Estados Unidos durmiendo en colchones sobre el suelo, al declarar toque de queda y ley seca. En Honduras, la tasa de mortalidad es la segunda más alta de la región por efecto de la enfermedad. Nicaragua es el caso más tremendo, pues el gobierno Ortega-Murillo se negó a desarrollar medidas de prevención contra el virus y, más bien, permitió reuniones públicas y alentó encuentros y marchas para mostrar que el país estaba feliz y unido viviendo el verano. Nicaragua es ahora el país centroamericano con una mayor tasa de mortalidad por efecto de la pandemia.

En Costa Rica, el gobierno actuó rápidamente cerrando las fronteras e implementando políticas de distanciamiento físico que han tenido frutos y han hecho al país tener la más baja tasa de mortalidad por COVID-19 de toda América, pero las elites económicas han aprovechado la coyuntura para plantear proyectos de "distanciamiento social" con fuertes ataques a la institucionalidad y a lo público. A pesar de que es el país con más casos reportados por COVID-19, eso se debe a que el sistema de salud público está presente en todo el territorio nacional y lleva adelante pruebas para detectar la enfermedad todos los días. Lamentablemente, las elites económicas han estado presionando al Gobierno desde el inicio de la cuarentena, para obligarlo a poner en su agenda legislativa medidas que solo consolidan 
las políticas liberales de los últimos años. Hoy, en medio de la pandemia, se ha desarrollado con mucha celeridad la flexibilización de las jornadas y contratos de trabajo en Costa Rica, que se vuelven similares a lo ocurrido en Gran Bretaña y Alemania en la década de 1990, cuando los trabajadores tuvieron que asumir varios tipos de trabajo al día, arruinando con eso su posibilidad de jornada de ocho horas y llevándose en el camino la posibilidad de descanso y de ocio. El miedo a la enfermedad y la imposibilidad de reuniones para protestar vuelven el contexto más problemático en este pequeño país con democracia tropical.

Así, la COVID-19, como hecho global, refrenda el planteamiento de Rosenberg y Golden (1992), para quienes las sociedades son el marco de referencia de las enfermedades, pero, a la vez, las enfermedades enmarcan la sociedad, por lo que estas relacionan diferentes actores sociales. En ese sentido, la pandemia obligó a una tregua social, sin duda, muy bien fundamentada, pero en algunos países la situación de emergencia se ha utilizado para perseguir líderes sociales y étnicos.

La situación de calles vacías y cierres totales de parques y plazas en América Central se parece más al ojo del huracán, que produce calma, pero que arrastra tras de sí más destrucción. La situación económica y social que vendrá después de la pandemia será terrible en esta región que ya estaba desarmada en términos económicos por efecto de las reformas neoliberales. Ya hay cálculos que indican que el porcentaje de pobreza y de pobreza extrema se elevará ampliamente en toda Centroamérica y que la recesión económica podría durar años.

\section{¿Qué hacer?}

Los gobiernos de la región tendrán que ingeniárselas para paliar los efectos de la enfermedad, a la vez que remedian las desigualdades que venían del pasado. Esto sin seguir la estrategia del país que había mostrado la hegemonía en la región, Estados Unidos, pero que ahora evidencia, en el contexto de una globalización en entredicho, las miserias de la riqueza generada en sociedades con alta desigualdad y en economías sustentadas en el consumo. Sería la oportunidad de China para asumir mayor presencia en América Central y portarse como una potencia colaboradora, al tiempo que remedia así parte de la culpa que se le imputa por haber acallado las primeras alertas internas sobre este nuevo coronavirus. Una tarea nada sencilla, que no se podrá llevar a cabo sin una gran ayuda internacional que involucrará moratorias de las deudas externas e internas y nuevas formas de financiación. Lo otro nada sencillo, en una región en la que los sectores ricos están acostumbrados a no pagar impuestos, es establecer un impuesto al capital bancario, de forma que con eso se pueda financiar parte de la recuperación económica y la ayuda a los grupos que más lo necesitan. Empero, las élites centroamericanas han corrido a autoprotegerse y lanzarle el costo de la crisis a los sectores medios y de asalariados. Por eso, la situación podría ser más difícil que durante la tremenda crisis de la década de 1980. Si no se operan esas transformaciones, el incendio social se convertirá en una catástrofe que solamente se podrá paliar mediante la construcción de una "nueva confianza" donde las elites egoístas centroamericanas se transformen, mínimamente, en elites progresistas. 


\section{Referencias}

Brown, W. (2009). Edgework: Critical Essays on Knowledge and Politics. Princeton, NJ: Princeton University Press.

CEPAL (2019). Panorama social de América Latina. Santiago: CEPAL.

Dardot, P., y Laval, C. (2016). La nouvelle raison du monde: essai sur la société néolibérale. Paris: La Découverte.

Díaz Arias, D. (2018). Nicaragua rebelde y reprimida, 2018. Istmo. Revista virtual de estudios literarios y culturales centroamericanos, (36), 213-221.

FMI (2012). Perspectivas de la economía mundial. Washington DC: Fondo Monerario Internacional, 85-89.

French, J.D. (2009). Understanding the Politics of Latin America's Plural Lefts (Chávez/Lula): Social Democracy, Populism and Convergence on the Path to a PostNeoliberal World. Third World Quarterly, 30(2), 349-370.

Kittrie, O. (2015). Lawfare. Law as weapon of war. London: Oxford University Press.

Lasch, C. (1995). The Revolt of the Elites and the Betrayal of Democracy. New York: W.W. Norton and Company.

Murillo, M.V. (2000). Del populismo al neoliberalismo: sindicatos y reformas de mercado en América Latina. Desarrollo Económico, 40(158), 179-212.

O’Donnell, G. (1994). Delegative Democracy. Journal of Democracy, 5(1), 55-69.

Proyecto Estado de la Nación (1999-2016). Estado de la Región. San José: Editorama S.A. Recuperado de https://www.estadonacion.or.cr/inicio/estado-region

Quinteros, M. C., y Viel Moreira, L. F. (Eds.). (2018). As revoluções na América Latina Contemporânea. Os desafios do século XXI. Maringá: Editora UEM/PGH/Historia.

Rosenberg, C., y Golden, J. (1992). Framing Disease: Studies in Cultural History. New Brunswick, NJ: Rutgers University Press. 